BMJ Open Diabetes Research \& Care

\title{
Recommendations for management of diabetes during Ramadan: update 2015
}

\author{
Mahmoud Ibrahim, ${ }^{1}$ Megahed Abu Al Magd, ${ }^{2}$ Firas A Annabi, ${ }^{3}$ \\ Samir Assaad-Khalil, ${ }^{4}$ Ebtesam M Ba-Essa, ${ }^{5}$ Ibtihal Fahdil, ${ }^{6}$ \\ Sehnaz Karadeniz, ${ }^{7}$ Terry Meriden, ${ }^{8}$ Aly A Misha'l, ${ }^{3}$ Paolo Pozzilli, ${ }^{9}$ \\ Samad Shera, ${ }^{10}$ Abraham Thomas, ${ }^{11}$ Suhad Bahijri, ${ }^{12}$ Jaakko Tuomilehto, ${ }^{13}$ \\ Temel Yilmaz, ${ }^{14}$ Guillermo E Umpierrez, ${ }^{15}$ on behalf of the International Group for \\ Diabetes and Ramadan (IGDR)
}

To cite: Ibrahim M, Abu A Magd M, Annabi FA, et al. Recommendations for management of diabetes during Ramadan: update 2015. BMJ Open Diabetes Research and Care 2015;3 e000108. doi:10.1136/ bmjdrc-2015-000108

Received 5 April 2015 Revised 2 June 2015 Accepted 3 June 2015

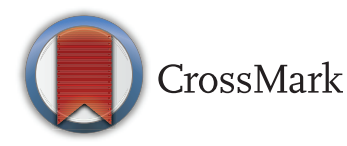

\section{SLinked}

- http://dx.doi.org/10.1136/ bmjdrc-2015-000111

For numbered affiliations see end of article.

Correspondence to Dr Mahmoud Ibrahim; mahmoud@arab-diabetes. com

\section{ABSTRACT}

Since the first ADA working group report on the recommendations for management of diabetes during Ramadan in 2005 and our update in 2010, we received many inquiries asking for regular updates on information regarding education, nutritional habits and new oral and injectable agents that may be useful for the management of patients with diabetes during Ramadan. Patients can be stratified into their risk of hypoglycemia and/or complications prior to the start of the fasting period of Ramadan. Those at high risk of hypoglycemia and with multiple diabetic complications should be advised against prolonged fasting. Even in the lower hypoglycemia risk group, adverse effects may still occur. In order to minimize adverse side effects during fasting in patients with diabetes and improve or maintain glucose control, education and discussion of glucose monitoring and treatment regimens should occur several weeks prior to Ramadan. Agents such as metformin, thiazolidinediones and dipeptidyl peptidase- 4 inhibitors appear to be safe and do not need dose adjustment. Most sulfonylureas may not be used safely during Ramadan except with extreme caution; besides, older agents, such as chlorpropamide or glyburide, should not be used. Reduction of the dosage of sulfonylurea is needed depending on the degree of control prior to fasting. Misconceptions and local habits should be addressed and dealt with in any educational intervention and therapeutic planning with patients with diabetes. In this regard, efforts are still needed for controlled prospective studies in the field of efficacy and safety of the different interventions during the Ramadan Fast.

\section{INTRODUCTION}

Since the ADA working group report on recommendations for management of diabetes during Ramadan published in 2005 and updated in 2010, many healthcare professionals have submitted inquiries asking for periodic updates every $3-5$ years to address the important management issues not covered in previous documents. ${ }^{12}$ Areas of interests include updates on lifestyle

\section{Key messages}

- The fasting period of Ramadan among Muslims requires special attention for diabetic patients in particular. This report provides an update for diabetes management recommendation during Ramadan.

- In order to minimize adverse events related to diabetes such as hypoglycaemia during fasting, patient education, regular glucose monitoring and adjustment of treatment regimens should occur weeks prior to Ramadan.

- Patients treated with sulfonylureas and insulin are at highest risk of hypoglycaemia, and such patients need careful blood glucose monitoring and, if necessary such treatment regimens may be adjusted.

intervention and use of new pharmacological agents for the treatment of diabetes. We reviewed the literature and reports on new published data on diabetes education, medical nutrition therapy, and recently introduced antidiabetic medications.

There are several potential benefits of fasting during Ramadan. Fasting helps Muslims to feel compassion for those who are less fortunate and underprivileged; it also allows one to build a sense of selfcontrol and willpower, and learn to control natural urges such as hunger and thirst. These benefits allow Muslims to better resist temptations for daily things that are not necessary, such as unhealthy or harmful substances and behaviors. Fasting also offers a time to 'purify' the body and the soul, by developing a greater sense of humility, spirituality, and community involvement. As for the potential physiological benefits, it is believed that intermittent fasting limits energy intake promoting weight loss in obese individuals, which could be cardioprotective. ${ }^{3}$ It is not known, however, what dietary changes have relevance, or positive or 
negative impacts on the management of diabetes during Ramadan. Significant nutritional changes obviously have a major impact on pharmacological and nonpharmacological management of diabetes.

\section{DIABETES EDUCATION DURING RAMIADAN}

Structured diabetes education is an essential tool for the management of diabetes during the fasting period and after breaking the fast during Ramadan. In a retrospective analysis by Bravis et al, ${ }^{4}$ patients who received diabetes education had less weight gain and fewer episodes of hypoglycemia compared with a group that did not receive education prior to Ramadan. Diabetes education, including the use of point-of-care (POC) glucose testing, resulted in fewer episodes of hypoglycemia between the start of Ramadan and the end of fasting. ${ }^{5}$ Diabetes education also helps to overcome certain barriers to diabetes care such as the misconception that puncturing one's skin for blood glucose testing during the fast would break the fast. ${ }^{6}$

\section{USE OF GLUCOSE-LOWERING MEDICATIONS DURING RAMIADAN}

The preferred antidiabetic drugs during Ramadan are agents that provide sustained glucose control during prolonged fasting with low risk of hypoglycemia, especially during the fasting period. Table 1 lists the benefits and concerns of commonly used oral antidiabetic agents during Ramadan.

Sulfonylureas and insulin secretagogues are widely used during Ramadan. Recent studies, however, have highlighted an increased risk of hypoglycemia during fasting in patients treated with insulin secretagogues. ${ }^{7-9}$ The risk of hypoglycemia increases exponentially in elderly patients and patients with renal failure and medical illnesses treated with sulfonylureas. In general, it is recommended that insulin secretagogues should be avoided during periods of prolonged fasting due to the increased risk of hypoglycemia. However, the STEADFAST study, a double-blind randomized controlled trial (RCT), compared vildagliptin with gliclazide as an add-on therapy to metformin during Ramadan. In that study, there were no significant differences in weight, glycated hemoglobin (HbAlc), or in the frequency of hypoglycemia between treatment groups. ${ }^{10}$

Metformin is the preferred agent for the management of patients with type 2 diabetes. Metformin is associated with a reduction in $\mathrm{HbAlc}$ of $1-2 \%$ and carries a low risk of hypoglycemia. ${ }^{11}$ These properties make metformin an attractive therapy for the majority of patients who will undergo prolonged fasting. It should be noted, however, that there are very few prospective RCT specifically designed to determine the safety and efficacy of metformin as monotherapy during Ramadan. ${ }^{12}$ The VECTOR study compared glipizide and vildagliptin in combination with metformin during Ramadan and reported low rates of hypoglycemia along with a lowering of the HbAlc concentration compared with the glipizide group. ${ }^{13}$ In these trials, no safety issues were found related to metformin use.

$\alpha$-Glucosidase inhibitors are used successfully in the Middle Eastern population during Ramadan. The most common adverse events with these agents are gastrointestinal symptoms, usually at the beginning of treatment. ${ }^{14}$ The risk of hypoglycemia is low when used as monotherapy; there are, however, no prospective studies looking at the safety and efficacy of these agents during prolonged fasting periods.

Thiazolidinediones (TZDs), such as pioglitazone, are effective in lowering glucose by improving glucose uptake in peripheral tissues and by reducing insulin resistance. The use of TZDs is not associated with increased risk of hypoglycemia when used as monotherapy. These agents are effective in improving glucose control, resulting in a reduction of HbA1c between $1 \%$ and 2\%. ${ }^{15}$ TZDs have long been thought of as a useful agent during Ramadan because of its low risk of hypoglycemia; however, these agents should be started long before the start of the fast as the maximal antihyperglycemic effect may take up to 10-12 weeks. In addition, long-term treatment with TZDs has been associated with fluid retention, peripheral edema, and weight gain. There is also concern with the higher risk of bone loss and increased risk of fractures seen in postmenopausal women. The safety and efficacy of TZD agents has not been established in clinical trials during Ramadan.

Dipeptidyl peptidase-4 (DPP4) inhibitors have been increasingly used during the past decade for the treatment of patients with type 2 diabetes during Ramadan. These agents work by increasing insulin secretion in a glucosedependent mechanism; therefore, they are not associated with increased risk of hypoglycemia when used as monotherapy. DPP4 inhibitors also reduce glucagon concentration and delay gastric emptying. These agents are attractive during Ramadan because of the low rate of hypoglycemia. Vildagliptin has been compared with different sulfonylurea agents, with and without metformin combination, during Ramadan. The results of these studies indicate that DPP4 inhibitors are effective in improving glycemic control with low rates of hypoglycemia and less weight gain compared with insulin secretagogues. ${ }^{10} 1316$ The vildagliptin expeRience compared wiTh sulfonylUrea obsErved during Ramadan (VIRTUE trial) that compared vildagliptin with sulfonylurea therapy during Ramadan reported a reduction in hypoglycemic events with the use of vildagliptin compared with sulfonylurea agents. ${ }^{16}$ Similar beneficial effects have also been reported with sitagliptin therapy during Ramadan. ${ }^{8}$

Few studies have determined the safety and efficacy of glucagon-like peptide 1 receptor agonists (GLP-1 RA) in patients with diabetes during Ramadan. A recent study of liraglutide compared with insulin secretagogues reported a significant improvement in glycemic control with weight loss with liraglutide treatment compared with patients treated with sulfonylureas. ${ }^{14}$ Severe 
Table 1 Pharmacological oral agents for the treatment of type 2 diabetes during Ramadan

\begin{tabular}{llll}
\hline Generic name & $\begin{array}{l}\text { Daily } \\
\text { dosage }(\mathrm{mg})\end{array} \quad$ Advantages & Concerns \\
\hline
\end{tabular}

\begin{tabular}{|c|c|c|}
\hline \multicolumn{3}{|c|}{$\begin{array}{l}\text { Insulin secretagogues } \\
\text { Sulfonvlureas }\end{array}$} \\
\hline Glipizide & $2.5-20$ & \multirow{5}{*}{$\begin{array}{l}\text { Lowers } \mathrm{HbA} 1 \mathrm{c} \text { by } 1-2 \% \text {, high initial } \\
\text { response rate, no lag time before } \\
\text { response, once-daily dosing, low cost }\end{array}$} \\
\hline Glyburide & $1.25-20$ & \\
\hline Glimepiride & $1-4$ & \\
\hline Gliclazide & $40-320$ & \\
\hline Gliclazide MR & $30-60$ & \\
\hline \multicolumn{3}{|l|}{ Meglitinides } \\
\hline Repaglinide & $0.5-8$ & Lowers $\mathrm{HbA} 1 \mathrm{c}$ by $1-1.5 \%$, shorter half- \\
\hline Nateglinide & $60-120$ & than sulfonylureas \\
\hline \multicolumn{3}{|c|}{$\alpha$-Glucosidase inhibitors } \\
\hline $\begin{array}{l}\text { Acarbose } \\
\text { Miglitol }\end{array}$ & $25-150$ & $\begin{array}{l}\text { Lowers } \mathrm{HbA} 1 \mathrm{c} \text { by } 0.5-0.8 \% \text { lowers } \\
\text { postprandial glucose levels without } \\
\text { causing hypoglycemia, weight neutral }\end{array}$ \\
\hline \multicolumn{3}{|l|}{ Insulin sensitizers } \\
\hline \multicolumn{3}{|l|}{ Biguanides } \\
\hline Metformin & 500-2000 & $\begin{array}{l}\text { Lowers } \mathrm{HbA} 1 \mathrm{c} \text { by } 1-2 \% \text {, weight neutral, } \\
\text { high initial response rate, long record of } \\
\text { relative safety, low risk of hypoglycemia, } \\
\text { improved lipid profile, may reduce } \\
\text { macrovascular events, low cost }\end{array}$ \\
\hline \multicolumn{3}{|c|}{ Thiazolidinediones } \\
\hline Pioglitazone & $15-45$ & $\begin{array}{l}\text { Lowers } \mathrm{HbA} 1 \mathrm{c} \text { by } 0.8-1.5 \% \text {, low risk of } \\
\text { hypoglycemia, improved lipid profile }\end{array}$ \\
\hline
\end{tabular}

Incretin agents

Dipeptidyl peptidase-4 inhibitors

$\begin{array}{ll}\text { Sitagliptin } & 25-100 \\ \text { Linagliptin } & 5 \\ \text { Saxagliptin } & 2.5-5 \\ \text { Alogliptin } & 12.5-25 \\ \text { Anagliptin* } & 200-400 \\ \text { Teneligliptin* } & 20-40 \\ \text { Glucagon-like peptide } 1 \text { agonists } \\ \text { Exenatide } & 5-10 \text { mcg two } \\ & \text { times a day } \\ \text { Liraglutide } & 0.6-1.8 \text { mg daily } \\ \text { Exenatide ER } & 2 \text { mg weekly } \\ \text { Dulaglutide } & 0.75-1.5 \text { mg } \\ & \text { weekly } \\ \text { Albiglutide } & 30 \text { mg weekly } \\ \text { Lixisenatide* } & 10 \text { mcg daily } \\ \text { SGLT-2 inhibitors } \\ \text { Dapagliflozin } & 5-10 \text { mg daily } \\ \text { Canagliflozin } & 100-300 \text { daily }\end{array}$

Lowers $\mathrm{HbA} 1 \mathrm{c}$ by $0.6-1 \%$, well tolerated, lowers postprandial glucose levels, weight neutral

Lowers $\mathrm{HbA} 1 \mathrm{c}$ by $0.8-2 \%$, lowers postprandial glucose levels, weight loss, low risk of hypoglycemia, may reduce blood pressure, improved lipid profile

Lowers $\mathrm{HbA} 1 \mathrm{c}$ by $0.8-1.5 \%$, low risk of hypoglycemia, weight loss, lower blood pressure
Hypoglycemia, weight gain, need caution in patients with renal and hepatic dysfunction and with sulfa allergy

Hypoglycemia, weight gain, repeated (before meals) dosing, more expensive than sulfonylureas

Less effective in lowering glycemia than metformin or sulfonylureas, increased gas production and $\mathrm{Gl}$ symptoms

Initial GI side effects common, risk of lactic acidosis, cannot be used in patients with renal dysfunction or hepatic dysfunction

Weight gain, fluid retention causing peripheral edema and/or heart failure, expensive, risk of osteopenia in postmenopausal females

More expensive and less potent than metformin and sulfonylureas, some agents require dose adjustment in patients with reduced renal function

High rate of GI side effects, injectable, more expensive than sulfonylureas and metformin

Increases risk of urinary tract infection and genital infections, expensive, risk of dehydration

*Not Food and Drug Administration approved.

ER, extended release; GI, glycemic index; HbA1c, glycated hemoglobin; MR, modified release; SGLT-2, sodium glucose transporter-2.

hypoglycemic events were not increased with either treatment, but self-reported hypoglycemia was lower with liraglutide. ${ }^{14}$

The sodium glucose transporter-2 (SGLT-2) inhibitors are the newest class of approved oral antidiabetic agents for the treatment of type 2 diabetes. By increasing glucosuria, SGLT-2 inhibitors are associated with significant improvements of fasting hyperglycemia and $\mathrm{HbAlc}$ concentration, and with low risk of hypoglycemia in patients with type 2 diabetes. These agents, however, are associated with increased risk of urinary tract and genital infections, and with a mild increase in the risk of 
volume contraction and dehydration. ${ }^{17}$ The lower rates of hypoglycemia compared with sulfonylurea and insulin treatment make SGLT-2 inhibitors an attractive drug in patients with diabetes during Ramadan. However, the associated volume contraction and risk of dehydration represent a concern during prolonged fasting in warm or hot climates, in particular in elderly patients. Randomized controlled studies are needed to determine the safety and efficacy of SGLT-2 inhibitors during Ramadan, especially after the recent Food and Drug Administration (FDA) warning concerning the possible ketoacidosis.

Type 2 diabetes is associated with a progressive decline in insulin secretion and $\beta$-cell loss with increased duration of diabetes. Many patients soon after a clinical diagnosis of diabetes need to be treated with insulin injections. Although effective in improving glucose control, insulin treatment is associated with increased risk of hypoglycemia, especially during prolonged fasting. The total insulin dose frequently needs to be adjusted during Ramadan in patients with type 1 or type 2 diabetes. The use of basal (glargine or detemir) and rapid-acting insulin analogs (lispro, aspart, and glulisine) has been shown to be superior to human insulin formulations (NPH and regular) during Ramadan by reducing the risk of hypoglycemia. In one study, the administration of lispro insulin before meals was associated with better glycemic control and with a lower rate of hypoglycemia compared with treatment with regular insulin. ${ }^{18}$ In another study, switching from premixed insulin formulation (30\% regular $/ 70 \% \quad \mathrm{NPH})$ to 50 regular/50NPH insulin during the evening meal demonstrated a reduction in HbAlc with less hypoglycemic episodes. $^{19}$

The use of insulin pump therapy has been shown to be effective in improving glycemic control and in reducing the risk of hypoglycemia in patients with type 1 diabetes during Ramadan. The use of an insulin pump helps to provide a continuous basal rate of insulin during the fasting period and to rapidly cover for meals intake after the breaking of the fast. In one study, patients on insulin pumps were monitored during Ramadan with a continuous glucose-monitoring (CGM) device. ${ }^{20}$ There was no significant increase in the risk of hypoglycemia when comparing the periods before, during, and after the end of fasting. However, the insulin infusion rate needs to be adjusted, with a reduction in the basal insulin rate during the day and greater postprandial boluses after the breaking of the fast. ${ }^{20}$ The use of CGM devices have evolved during the past decade from being a research tool to serving as a device useful for clinical care in patients with type 1 and type 2 diabetes. CGM devices provide information about the current glucose concentration, direction, and rate of change in glucose concentration. Since it provides glucose values every $5-10 \mathrm{~min} 24 \mathrm{~h}$ a day, CGM may have an advantage over POC testing with respect to reducing the incidence of severe hypoglycemia during fasting. A recent report reported that the use of CGM reported benefits in detecting hypoglycemia during fasting in insulin-treated patients. ${ }^{21}$ No randomized controlled studies, however, have studied the impact of CGM in patients with diabetes during Ramadan.

Premixed insulin is a commonly prescribed formulation for the outpatient management of patients with type 2 diabetes. In many Muslim countries, premixed insulins are among the most frequently prescribed formulations in patients with type 2 diabetes. Of concern is the fact that some studies have reported a higher risk of hypoglycemia with the use of premixed insulin formulations compared with basal insulin analogs. ${ }^{22}$ The safety and efficacy of premixed insulin formulations during Ramadan is not known. Table 2 lists recommendations for insulin self-titration during the Ramadan period. The 'Low-Ratio Premix Insulin Working Group' recently reported a practical outline on how to adjust insulin during the fasting period, based on premeal blood glucose levels and the history of hypoglycemia. ${ }^{23}$ This group also recommended a trial fast for three consecutive days before Ramadan to help in detecting hypoglycemia risk and for guiding the self-titration of premix insulin dosage.

Illustrative examples for risks and recommendations for adjusting glucose-lowering therapy during Ramadan in patients with type 2 diabetes are shown in the management algorithm flow chart (figure 1).

\section{MEDICAL NUTRITION THERAPY DURING RAMIADAN}

A number of dietary interventions have been shown to be effective in the management of patients with type 2 diabetes. Of particular interest for Ramadan, the use of the macrobiotic Ma-Pi 2 diet may be considered. ${ }^{24}$ This diet, conceived by Mario Pianesi, is high in dietary fibers, which is in keeping with the ADA and European nutrition recommendations. ${ }^{25}$ It is rich in complex carbohydrates, whole grains, vegetables and legumes, and

Table 2 Algorithm for premixed insulin titration during Ramadan (adapted from Hassanein et $a^{R^{3}}$ )

\begin{tabular}{ll}
\hline $\begin{array}{l}\text { Fasting pre-Iftar } \\
\text { pre-Suhoor BG }\end{array}$ & Insulin adjustment \\
\hline$>16.6 \mathrm{mmol} / \mathrm{L}(300 \mathrm{mg} / \mathrm{dL})$ & $\begin{array}{l}\text { Increase insulin daily dose } \\
\text { by } 20 \%\end{array}$ \\
$>10 \mathrm{mmol} / \mathrm{L}(180 \mathrm{mg} / \mathrm{dL})$ & $\begin{array}{l}\text { Reduce insulin daily dose } \\
\text { by } 10 \%\end{array}$ \\
$5.5-10 \mathrm{mmol} / \mathrm{L}(100-$ & No change \\
$180 \mathrm{mg} / \mathrm{dL})$ & $\begin{array}{l}\text { Reduce insulin daily dose } \\
<5.5 \mathrm{mmol} / \mathrm{L}(100 \mathrm{mg} / \mathrm{dL})\end{array}$ \\
symptoms & $\begin{array}{l}\text { Reduce insulin daily dose } \\
<3.9 \mathrm{mmol} / \mathrm{L}(70 \mathrm{mg} / \mathrm{dL})\end{array}$ \\
$<2.8 \mathrm{mmol} / \mathrm{L}(50 \mathrm{mg} / \mathrm{dL})$ & $\begin{array}{l}\text { beduce insulin daily dose } \\
\text { by } 30-40 \%\end{array}$ \\
\hline
\end{tabular}




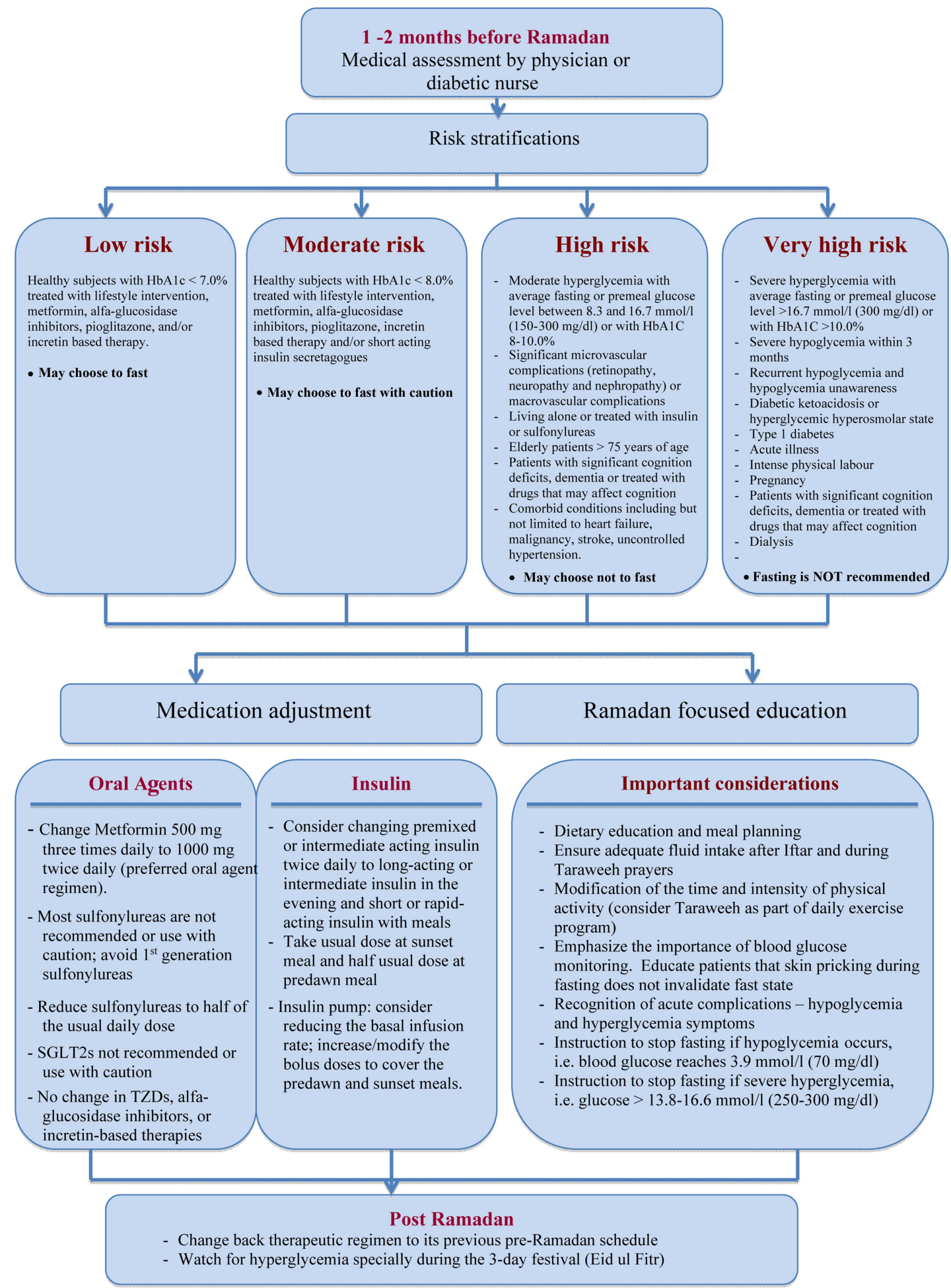

Figure 1 Management algorithm for people with type 2 diabetes intending to fast during Ramadan (HbA1c, glycated hemoglobin; SGLT-2, sodium glucose transporter-2 inhibitors; TZD, thiazolidinedione).

fermented products, and low in unrefined sea salt and green tea, without fat or protein from animal sources (including milk and dairy products) and no added sugars. ${ }^{24}$ The first RCT comparing the Ma-Pi 2 diet and a standard diet recommended for patients with type 2 diabetes-the MAcrobiotic DIABetes trial MADIAB—was reported in $2014 .{ }^{24}$ Following 21 days on the prescribed diets, administered under supervised conditions, the average daily energy intake was $1803 \mathrm{kcal}(12 \%$ protein, $15 \%$ fat, and $73 \%$ complex carbohydrates, with $29 \mathrm{~g} /$ $1000 \mathrm{kcal}$ fiber) in the Ma-Pi 2 group and $1798 \mathrm{kcal}$ ( $18 \%$ protein, $32 \%$ fat, and $49 \%$ complex carbohydrates, 
with $20.5 \mathrm{~g} / 1000 \mathrm{kcal}$ fiber) in the control group. Multivariate analysis, adjusted for age, gender, body mass index, and physical activity, showed a significant improvement in fasting blood glucose, postprandial blood glucose, HbAlc, total cholesterol, low-density lipoprotein (LDL) cholesterol, LDL-HDL (high-density lipoprotein) ratio, body weight, waist and hip circumference, and insulin resistance in the Ma-Pi 2 diet treated compared with the control diet. Furthermore, participants in the Ma-Pi 2 group achieved better fasting and postprandial glucose target levels of $6.1 \mathrm{mmol} / \mathrm{L}$ and $7.8 \mathrm{mmol} / \mathrm{L}(<110 \mathrm{mg} / \mathrm{dL}$ and $<140 \mathrm{mg} / \mathrm{dL})$, respectively, at the end of the 21-day dietary treatment, as well as a reduction of markers of insulin resistance and inflammation. ${ }^{24-26}$ These features are valuable in the management of type 2 diabetes during Ramadan due to a lower component of complex carbohydrate at the night meal and higher complex carbohydrate at predawn, which is eaten before the beginning of daily fasting.

\section{DATES CONSUMIPTION}

Daily consumption of dates is a deeply rooted tradition among Muslims, especially during the Ramadan. Most Muslims consume dates when they break their fast (Iftar), either alone or with other food items such as yoghurt. Some people also consume dates at the predawn meal (Suhoor). Dehydrated dates (Tamer) analysis revealed that they are rich in carbohydrates (total sugars: 44-88\%), salts, minerals, vitamins, unsaturated fatty acids $(0.2-0.5 \%)$, proteins $(2-6 \%)$, and fibers $(6-12 \%)$.

Consumption of $100 \mathrm{~g}$ of dates provides $50-100 \%$ of the recommended dietary fiber intake. ${ }^{27}$ In addition, dates have high fructose content with a 1:1 ratio of fructose and glucose. Since fructose is a more powerful sweetener than glucose, it is less rapidly absorbed than sugar, which results in a relatively low glycemic index (GI) ${ }^{27} 28$ The GI of most common dates range between 35 and 55, with an average of $42 .^{29}{ }^{30}$ There is growing evidence of the beneficial effects of dates in improving glycemic and lipid control in patients with diabetes and a possible reduction in cardiovascular risk factors. ${ }^{29}$ More research; however, is needed to study the possible beneficial effects of dates on patients with diabetes during Ramadan.

\section{TARAWEEH PRAYERS}

These are long night prayers, which are not obligatory but highly recommended, that last for 1-2 $\mathrm{h}$. Taraweeh prayers can be a strenuous physical activity that could result in dehydration and increased risk of hypoglycemia. Taraweeh prayers should be considered as a part of the daily exercise program. So patients are advised to monitor BG concentration, to eat starchy foods with Iftar, which are digested slowly, and to drink plenty of water before prayers. In addition, patients with diabetes should be advised to consume extra fluids and carbohydrates to treat hypoglycemic events during Taraweeh prayers. Patients with diabetes at risk or with a history of severe or recurrent hypoglycemia should be treated with agents with a low risk of hypoglycemia or advised to reduce the total daily dose of insulin during Ramadan and Taraweeh prayers. ${ }^{31}$

\section{MISCONCEPTIONS ABOUT DRAWING BLOOD AND INSULIN INJECTIONS DURING THE FAST}

Contrary to the widespread belief among some Muslim communities that injection invalidates the fast, patients should be instructed that insulin injections have no nutrition value and that they are allowed, regardless of whether they are given by the subcutaneous, intramuscular, or intravenous route. ${ }^{32}$

There is a popular belief that pricking the finger for POC testing breaks the fast, which may lead to patients skipping glucose testing during Ramadan. Again, patients and family members should be educated that similar to injections, puncturing the skin with glucose monitoring devices are allowed, and that glucose monitoring may help in assessing glucose control and in recognizing hypoglycemia during Ramadan. A retrospective study assessed the beliefs and practices of people with diabetes about skin pricking for blood glucose testing during Ramadan fasting. Despite $57 \%$ of the study population being literate, $77 \%$ of patients did not perform blood glucose monitoring. A large number of patients with diabetes who did not perform monitoring believed that skin pricking during fasting would make the fast void; as a consequence, $40 \%$ of participants who were taking insulin never checked their blood glucose levels during fasting. ${ }^{6}$ The low rates of glucose monitoring may result in a higher risk of hypoglycemia in insulintreated patients with diabetes. ${ }^{33}$

To prevent hypoglycemia in diabetes during fasting, healthcare providers need to emphasize the importance of regular glucose monitoring for maintenance of normoglycemia and that skin pricking during fasting does not invalidate the fasting state. ${ }^{34}$ All people with diabetes who choose to fast should be trained to monitor their blood glucose, to recognize symptoms and signs of hypoglycemia, and to learn about the management and risks associated with severe hypoglycemic events. In addition, patients should be counseled about breaking the fast in the presence of hypoglycemia. ${ }^{35}$

\section{LIFESTYLE CHANGES AFTER RAMADAN}

The end of Ramadan is followed by a 3-day festival known as Eid ul-Fitr. This is usually marked with festivities, sharing of food, and sweet beverages. Patients with diabetes should be advised about the risks of hyperglycemia during this time, as many individuals overindulge in eating and drinking. When the month of Ramadan ends, the patients' therapeutic regimen should be adjusted and may be changed back to its previous 
schedule, if glycaemic control was satisfactory before Ramadan. ${ }^{31}$

\section{ADDITIONAL REGIONAL PECULIARITIES \\ Egypt}

According to the latest version of the International Diabetes Federation Atlas, the number of adult people with diabetes in Egypt is approximately 7.6 million. ${ }^{36}$ The vast majority of Muslims with diabetes will practice fasting during the month of Ramadan, even in the presence of diabetic complications. People from some Gulf and North African countries break the fast in the evenings with water and light snacks, followed by consumption of the main meal $\sim 2 \mathrm{~h}$ after breaking the fast. In contrast, people in Egypt consume the main meal immediately after breaking the fast. Of interest, physicians should be aware that many people in Egypt during Ramadan consume an extra meal after midnight, replacing the predawn meal, while others may skip the predawn meal. These differences in nutritional intake may have an impact on the management of patients with diabetes and require medication adjustments to maintain glucose control and diminish the risk of hypoglycemia. Unfortunately, no previous studies have reported on the best treatment regimens in different Muslim populations during Ramadan.

\section{Turkey}

In Turkey, despite Islam being the most prevalent religion, no previous studies have investigated the effects of fasting on glucose control or the availability of diabetes education. Some small short-term studies have reported no significant effects of fasting on metabolic parameters including glucose control and weight change between the start of fasting and the end of Ramadan in patients with type 2 diabetes. ${ }^{37}$ Of interest, despite the fact that the majority of patients in these studies were treated with a variety of oral antidiabetic agents, the rate of hypoglycemia is low with few patients experiencing glucose levels of less than $2.2 \mathrm{mmol} / \mathrm{L}(40 \mathrm{mg} / \mathrm{dL})$ or symptoms of neuroglycopenia. ${ }^{37} 38$

\section{Ramadan in the United Arab Emirates}

In the United Arab Emirates (UAE), Ramadan is a spiritual and a festive season. The sunset meal starts with dates followed by a heavier and often carbohydrate-rich meal. A pre-Ramadan medical consultation happens in the minority of patients and often involves patients receiving multiple medications, as well as those having chronic diabetic complications and at risk or with a history of hypoglycemia. A recent study on the use of CGM in the UAE provided insights into the nature of glucose variability among patients with diabetes during Ramadan. ${ }^{39}$ This study, which was conducted in 56 patients with diabetes with good glycemic control before fasting, showed no significant differences in glycemic control or in the number of large glucose excursions between the pre-Ramadan and Ramadan periods. ${ }^{21} 39$ It showed worse glycemic control in insulin-treated and sulfonylurea-treated patients compared with those on DPP4 inhibitors, metformin, or diet alone. These differences in glycemic control were exaggerated during Ramadan fasting and were more pronounced after Iftar. ${ }^{21} 39$

\section{Ramadan in Pakistan}

Approximately $96.4 \%$ of the population of Pakistan is Muslim. Few studies have reported on glucose control or the impact of Ramadan on diabetes control in this population. Approximately $73 \%$ of patients with diabetes in Pakistan undergo fasting during the month of Ramadan, with a mean age of $50.3 \pm 13$ years. Among them, $4 \%$ have type 1 diabetes and $96 \%$ have type 2 diabetes. In Pakistan, patients with diabetes fast for an average of 20-25 days during the month of Ramadan. While the prevalence of hypoglycemia and hyperglycemia has been reported in $4 \%$ and $8 \%$, respectively, only $23 \%$ of patients with diabetes practice glucose monitoring during the fasting period. ${ }^{40}$ One study reported that $18 \%$ of patients experience one or more episodes of hypoglycemia during the Ramadan period; however, most patients with hypoglycemia did not break their fast. ${ }^{33}$ Of interest, there does not appear to be a significant difference in the total number of calories consumed during the Ramadan period, and it is not clear if there is a significant difference in glucose control during the fasting period. ${ }^{40}$ In addition, few patients require hospitalization for glycemic irregularities during fasting, and there are no increased rates of diabetic ketoacidosis during fasting.

\section{RECOMIMENDATIONS FOR THE PREVENTION AND TREATMENT OF HYPOGLYCEMIA DURING RAMADAN}

Box 1 lists the recommendations for prevention of hypoglycemia during the Ramadan season. In general,

Box 1 Recommendations for prevention of hypoglycemia during Ramadan

Blood glucose monitoring. Depending on treatment regimen, monitor glucose levels daily or several times a day. Patients treated with insulin and insulin secretagogues should measure glucose before, during, and after fasting (2-4 times daily)

- Consultation with diabetes healthcare provider for medication adjustment. Treatment regimen should be evaluated and modified according to glycemic control and risk of hypoglycemia, at least 1 month prior to Ramadan. Avoid or reduce sulfonylureas and/or insulin daily dosage

Avoid skipping predrawn meals

Avoid strenuous physical activity during fasting period

- Adjust medication dose and eat a snack in the presence of hypoglycemia (see box 2). Consider breaking the fast if there is severe or recurrent hypoglycemia

- Record blood glucose measures to determine patterns contributing to hypoglycemia 
Box 2 Recommendations for treatment of hypoglycemia

The following are examples of $15 \mathrm{~g}$ of carbohydrate:

- Four ounces (1/2 cup) of apple or orange juice

- Four ounces (1/2 cup) of regular sweetened soda

- Three or four glucose tablets

- One serving of glucose gel-the amount equal to $15 \mathrm{~g}$ of carbohydrate

Eight ounces (1 cup) of milk

Five or six pieces of hard candy

One tablespoon of sugar or honey

patients should be instructed on the use of glucose monitoring and frequency of glucose testing. Patients receiving insulin or insulin secretagogues should be monitored 2-4 times daily before, during, and after the fasting period. Patients treated with diet or with agents associated with a low risk of hypoglycemia should monitor their glucose levels once or twice daily to assess glucose control.

Patients and family members should receive instructions on treatment of hypoglycemia. A common error is to overtreat hypoglycemia with an excess intake of carbohydrate. Box 2 lists the common sources of $15 \mathrm{~g}$ of carbohydrates that are usually sufficient to correct mild-to-moderate hypoglycemic events. After treatment of any hypoglycemic episode, glucose levels should be repeated after $15 \mathrm{~min}$, and every 15-30 min thereafter, until a stable glucose level is achieved. Depending on the time of day and insulin peak times, a balanced snack with carbohydrate, protein, and fat (ie, peanut butter and crackers, or milk) can prolong treatment effectiveness. Patients with severe hypoglycemia may be treated with glucagon (1 mg), intramuscularly or subcutaneously, and may require hospitalization. Patients with severe hypoglycemia or with repeated hypoglycemic events should be counseled to avoid fasting during Ramadan.

\section{CONCLUSION}

Much of what is recommended for the management of patients with diabetes during fasting in Ramadan is based on expert opinion, and few randomized controlled studies have investigated best treatment regimens during Ramadan in patients with diabetes. Yet, since the last consensus publication, several antidiabetic medications have become available for the treatment of patients with diabetes.

Patients should be stratified into their risk of hypoglycemia and/or the presence of complications prior to the beginning of fasting. Patients at high risk of hypoglycemia and with multiple diabetic complications should be advised against prolonged fasting. Agents such as metformin, $\alpha$-glucosidase inhibitors, TZDs, and DPP4 inhibitors appear to be safe and do not need major dose adjustments. Sulfonylureas and insulin secretagogues should be used with extreme caution during Ramadan fasting, in particular chlorpropamide or glyburide, which are associated with increased risk of hypoglycemia. The dose of sulfonylureas should be reduced or the medication stopped before the start of the fast, depending on the degree of glycemic control, kidney function, and presence of diabetic complications. There is increasing knowledge on the efficacy and safety of DPP4 inhibitors as monotherapy or in combination with metformin therapy. The use of DPP4-inibitors appears to be safe and with low rates of hypoglycemia. The use of GLP-1 RA may also be of benefit in obese patients in improving glycaemic control and in reducing appetite during Ramadan. There is no data on the safety and efficacy of SGLT-2 inhibitors during the fasting period of Ramadan.

Patients with type 1 and type 2 diabetes treated with insulin should be educated on the appropriate use of insulin administration and the need for glucose monitoring during the fasting period. Most patients require a modification of the basal insulin dosage and on the use of premeal insulin to cover meals after breaking of the fast. In some patients, a larger insulin dose may be needed after a large evening meal. The use of basal insulin analogs and continuous insulin infusion may be of benefit as they cover basal requirements without significant peaks and may result in less hypoglycemia compared with human NPH and premixed insulin. The drawbacks of insulin analogs and insulin pump therapy are the cost and limitations of technology support in some countries. Finally, patients should be instructed that POC testing does not break the fast and that glucose monitoring may reduce the risks of hypoglycemia in patients receiving insulin secretagogues and insulin therapy.

\section{Author affiliations}

${ }^{1} \mathrm{EDC}$, Center for Diabetes Education, McDonough, Georgia, USA

${ }^{2}$ Department of Internal Medicine, Mansura University, Mansura, Egypt

${ }^{3}$ Islamic Hospital, Amman, Jordan

${ }^{4}$ Department of Internal Medicine, Unit of Diabetes \& Metabolism, Alexandria

Faculty of Medicine, Alexandria, Egypt

${ }^{5}$ Dammam Medical Complex, Dammam, Saudi Arabia

${ }^{6}$ Eastern Mediterranean Office of the World Health Organization, Cairo, Egypt

${ }^{7}$ Florence Nightingale Istanbul Hospital, Istanbul, Turkey

${ }^{8}$ Division of Endocrinology, University of IL, Chicago, Illinois, USA

${ }^{9}$ Department of Endocrinology and Metabolism, University Campus Bio Medico, Rome, Italy

${ }^{10}$ Diabetic Association of Pakistan, Karachi, Pakistan

${ }^{11} \mathrm{NYU}$ Lutheran, Brooklyn, New York, USA

${ }^{12}$ Saudi Diabetes Group, King Abdul Aziz University, Jeddah, Saudi Arabia

${ }^{13}$ National Institute for Health and Welfare, Helsinki, Finland

${ }^{14}$ Division of Endocrinology and Metabolism, Department of Internal

Medicine, Istanbul University, Istanbul, Turkey

${ }^{15}$ Emory University School of Medicine, Atlanta, Georgia, USA

Contributors MI, JT, and GEU wrote the initial draft of the manuscript. MAAM, FAA, SA-K, EMB-E, IF, SK, TM, AAM, PP, SS, AT, and SB reviewed and edited the manuscript.

Funding GEU is supported in part by research grants from the American Diabetes Association (1-14-LLY-36), and PHS grant UL1 RR025008 from the Clinical and Translational Science Award program, National Institutes of Health, National Center for Research Resources.

Competing interests GEU has received unrestricted research support for inpatient studies (to Emory University) from Sanofi, Merck, Novo Nordisk, 
Boehringer Ingelheim, and has received consulting fees and/or honoraria for membership in advisory boards from Novo Nordisk, Sanofi, Merck, and Boehringer Ingelheim.

Provenance and peer review Not commissioned; externally peer reviewed.

Data sharing statement No additional data are available.

Open Access This is an Open Access article distributed in accordance with the Creative Commons Attribution Non Commercial (CC BY-NC 4.0) license, which permits others to distribute, remix, adapt, build upon this work noncommercially, and license their derivative works on different terms, provided the original work is properly cited and the use is non-commercial. See: http:// creativecommons.org/licenses/by-nc/4.0/

\section{REFERENCES}

1. Al-Arouj M, Bouguerra R, Buse J, et al. Recommendations for management of diabetes during Ramadan. Diabetes Care 2005;28:2305-11.

2. Al-Arouj M, Assaad-Khalil S, Buse J, et al. Recommendations for management of diabetes during Ramadan: update 2010. Diabetes Care 2010;33:1895-902.

3. Brown JE, Mosley M, Aldred S. Intermittent fasting: a dietary intervention for prevention of diabetes and cardiovascular disease? Br J Diab Vasc Dis 2013;13:68-72.

4. Bravis V, Hui E, Salih S, et al. Ramadan Education and Awareness in Diabetes (READ) programme for Muslims with type 2 diabetes who fast during Ramadan. Diabet Med 2010;27:327-31.

5. Ahmedani MY, Haque MS, Basit A, et al. Ramadan Prospective Diabetes Study: the role of drug dosage and timing alteration, active glucose monitoring and patient education. Diabet Med 2012:29:709-15.

6. Masood SN, Sheikh MA, Masood Y, et al. Beliefs of people with diabetes about skin prick during Ramadan fasting. Diabetes Care 2014;37:e68-9.

7. Anwar A, Azmi K, Hamidon B, et al. An open label comparative study of glimepiride versus repaglinide in type 2 diabetes mellitus Muslim subjects during the month of Ramadan. Med J Malaysia 2006;61:28-35.

8. Aravind $\mathrm{S}$, Ismail SB, Balamurugan $\mathrm{R}$, et al. Hypoglycemia in patients with type 2 diabetes from India and Malaysia treated with sitagliptin or a sulfonylurea during Ramadan: a randomized, pragmatic study. Current Med Res Opin 2012;28:1289-96.

9. Glimepiride in Ramadan (GLIRA) Study Group. The efficacy and safety of glimepiride in the management of type 2 diabetes in Muslim patients during Ramadan. Diabetes Care 2005;28:421-2.

10. Hassanein M, Abdallah K, Schweizer A. A double-blind, randomized trial, including frequent patient-physician contacts and Ramadan-focused advice, assessing vildagliptin and gliclazide in patients with type 2 diabetes fasting during Ramadan: the STEADFAST study. Vasc Health Risk Manag 2014;10:319-26.

11. Wright AD, Cull CA, Macleod KM, et al. Hypoglycemia in type 2 diabetic patients randomized to and maintained on monotherapy with diet, sulfonylurea, metformin, or insulin for 6 years from diagnosis: UKPDS73. J Diabetes Complications 2006;20:395-401.

12. Al Sifri S, Basiounny A, Echtay A, et al. The incidence of hypoglycaemia in Muslim patients with type 2 diabetes treated with sitagliptin or a sulphonylurea during Ramadan: a randomised trial. Int J Clin Pract 2011;65:1132-40.

13. Hassanein M, Hanif W, Malik W, et al. Comparison of the dipeptidyl peptidase-4 inhibitor vildagliptin and the sulphonylurea gliclazide in combination with metformin, in Muslim patients with type 2 diabetes mellitus fasting during Ramadan: results of the VECTOR study. Cur Med Res Opin 2011;27:1367-74.

14. Brady EM, Davies MJ, Gray LJ, et al. A randomized controlled trial comparing the GLP-1 receptor agonist liraglutide to a sulphonylurea as add on to metformin in patients with established type 2 diabetes during Ramadan: the Treat 4 Ramadan Trial. Diab Obes Metab 2014:16:527-36.

15. Jain R, Osei K, Kupfer S, et al. Long-term safety of pioglitazone versus glyburide in patients with recently diagnosed type 2 diabetes mellitus. Pharmacotherapy 2006;26:1388-95.
16. Al-Arouj M, Hassoun AAK, Medlej R, et al. The effect of vildagliptin relative to sulphonylureas in Muslim patients with type 2 diabetes fasting during Ramadan: the VIRTUE study. Int $J$ Clin Pract 2013;67:957-63.

17. Chao EC. SGLT-2 inhibitors: a new mechanism for glycemic control. Clin Diab 2014;32:4-11.

18. Kadiri A, Al-Nakhi A, El-Ghazali S, et al. Treatment of type 1 diabetes with insulin lispro during Ramadan. Diabetes Metab 2001;27(4 Pt 1):482-6.

19. Hui E, Bravis V, Salih S, et al. Comparison of Humalog Mix 50 with human insulin Mix 30 in type 2 diabetes patients during Ramadan. Int J Clin Pract 2010;64:1095-9.

20. Khalil AB, Beshyah SA, Abu Awad SM, et al. Ramadan fasting in diabetes patients on insulin pump therapy augmented by continuous glucose monitoring: an observational real-life study. Diabetes Technol Ther 2012;14:813-18.

21. Lessan N, Hannoun Z, Hasan $\mathrm{H}$, et al. Glucose excursions and glycaemic control during Ramadan fasting in diabetic patients: insights from continuous glucose monitoring (CGM). Diabetes Metab 2015;41:28-36

22. Garber AJ, Ligthelm R, Christiansen JS, et al. Premixed insulin treatment for type 2 diabetes: analogue or human? Diabetes Obes Metab 2007;9:630-9.

23. Hassanein M, Belhadj M, Abdallah K, et al. Management of type 2 diabetes in Ramadan: low-ratio premix insulin working group practical advice. Indian J Endocrinol Metab 2014:18:794-9.

24. Porrata-Maury C, Hernández-Triana M, Ruiz-Álvarez V, et al. Ma-Pi 2 macrobiotic diet and type 2 diabetes mellitus: pooled analysis of short-term intervention studies. Diabetes Metab Res Rev 2014;30 (S1):55-66.

25. Soare A, Khazrai YM, Del Toro R, et al. The effect of the macrobiotic Ma-Pi 2 diet vs. the recommended diet in the management of type 2 diabetes: the randomized controlled MADIAB trial. Nutr Metab 2014;11:39.

26. Soare A, Del Toro R, Roncella E, et al. The effect of macrobiotic Ma-Pi 2 diet on systemic inflammation in patients with type 2 diabetes: a post hoc analysis of the MADIAB trial. BMJ Open Diabetes Res Care 2015;3:e000079.

27. Alkaabi JM, Al-Dabbagh B, Ahmad S, et al. Glycemic indices of five varieties of dates in healthy and diabetic subjects. Nutr $J$ 2011;10:59

28. Miller CJ, Dunn EV, Hashim IB. Glycemic index of 3 varieties of dates. Saudi Med J 2002;23:536-8.

29. Al-Farsi MA, Lee CY. Nutritional and functional properties of dates: a review. Crit Rev Food Sci Nutr 2008;48:877-87.

30. Atkinson FS, Foster-Powell K, Brand-Miller JC. International tables of glycemic index and glycemic load values: 2008. Diabetes Care 2008;31:2281-3.

31. Karamat MA, Syed A, Hanif W. Review of diabetes management and guidelines during Ramadan. J R Soc Med 2010;103:139-47.

32. Muslim Health Service. http://www.muslimhealthservice.com/ accessed January 25th 2015

33. Beshyah S, Benbarka M, Sherif I. Practical management of diabetes during Ramadan fast. Libyan J Med 2007;2:185-9.

34. Masood SN, Masood Y, Mumtaz SN, et al. Ramadan fasting related awareness, practices and experiences of a representative group of Urban Pakistani Diabetics. Pak J Med Sci 2012;28:432-6.

35. Jaleel MA, Raza SA, Fathima FN, et al. Ramadan and diabetes: As-Saum (the fasting). Indian $J$ Endocrinol Metab 2011;15:268.

36. IDF Atlas, 6th edn. http://www.idf.org/sites/default/files/Atlas-poster2014 EN.pdf (accessed 10 Feb 2015)

37. Sari $\bar{R}$, Balci MK, Akbas $\mathrm{SH}$, et al. The effects of diet, sulfonylurea and repaglinide therapy on clinical and metabolic parameters in type 2 diabetic patients during Ramadan. Endocr Res 2004;30:169-77.

38. Çelik S, Pinar R, Üzüm AK, et al. Effects of Ramadan fasting on daily life and metabolic condition in patients with type 2 diabetes. Turkiye Klinikleri J Med Sci 2013;33:1266-73.

39. Lessan N, Hasan H, Barakat MT. Ramadan fasting: a study of changes in glucose profiles among patients with diabetes using continuous glucose monitoring. Diabetes Care 2012;35:e37.

40. Ahmadani MY, Riaz M, Gul A, et al. Clinical profile of fasting diabetic subjects during Ramadan. J Coll Physicians Surg Pak 2007; 17:446-7. 